\title{
Effect of Nitrogen Fertilization on Disease Progress of Rice Blast on Susceptible and Resistant Cultivars
}

\author{
D. H. Long, Research Specialist, Department of Plant Pathology, University of Arkansas, Fayetteville 72701; F. N. \\ Lee, Professor, Rice Research and Extension Center, Stuttgart, AR 72160; and D. O. TeBeest, Professor, Depart- \\ ment of Plant Pathology, University of Arkansas, Fayetteville 72701
}

\begin{abstract}
Long, D. H., Lee, F. N., and TeBeest, D. O. 2000. Effect of nitrogen fertilization on disease progress of rice blast on susceptible and resistant cultivars. Plant Dis. 84:403-409.

The effects of three nitrogen fertilization treatments on the development of rice blast were studied on eight cultivars under field conditions in Arkansas in 1995 and 1996. The eight cultivars (Kaybonnet, Cypress, Lacassine, Mars, Adair, Alan, Newbonnet, and RT7015) ranged from resistant to susceptible to blast according to previous field observations. The recommended nitrogen levels for the eight cultivars varied from 123 to $168 \mathrm{~kg} / \mathrm{ha} / \mathrm{year}$. Three treatments, consisting of different rates and timing of nitrogen applications, were tested over 2 years at one location. The first treatment consisted of a single nitrogen (N) application applied to plots at the recommended rate at preflood during the midtillering stage. The second treatment consisted of applying nitrogen as a single preflood application but at 1.5 times the recommended $\mathrm{N}$ rate used in treatment one. The third treatment (control) consisted of applying the recommended amount of nitrogen fertilizer used in treatment one, but in a three-way-split application with 56 to 100 $\mathrm{kg} / \mathrm{ha}$ (depending on the cultivar) of urea applied at preflood followed by the application of 34 $\mathrm{kg} / \mathrm{ha}$ of $\mathrm{N}$ applied approximately 10 and 20 days after the panicle differentiation (PD) growth stage. Inoculated spreader plots were used to initiate rice blast epidemics in the test plots. The results indicate that the disease progress for rice blast, regardless of $\mathrm{N}$ treatments, followed a unimodal curve, whereby disease incidence and total lesion area per plant reached a maximum near midseason (PD growth stage) and then gradually declined. This decline in disease was attributed to adult resistance, leaf senescence, and the formation of new (noninfected) leaves. Application of nitrogen above the recommended rate for any given cultivar significantly increased disease incidence and total lesion area per plant on all cultivars except Kaybonnet, a highly resistant cultivar. Furthermore, a differential cultivar response to nitrogen was observed when measuring both disease incidence and total lesion area per plant. Leaf blast was significantly more severe on the susceptible and very susceptible cultivars when $\mathrm{N}$ fertilizer was applied as a single application at preflood than in the split application treatment. Nitrogen treatments did not significantly affect the incidence of collar rot or neck blast.
\end{abstract}

Additional keywords: Magnaporthe grisea, Oryza sativa, Pyricularia grisea

Rice blast is one of the most destructive diseases of rice (Oryza sativa L.) worldwide and can result in significant reduc-

Corresponding author: D. O. TeBeest

E-mail: dtebeest@comp.uark.edu

Portion of an M.S. thesis submitted by the senior author in partial fulfillment of the requirements of the University of Arkansas.

Research supported in part by a grant from the Arkansas Rice Research Promotion Board.

Published with the approval of the Director of the Arkansas Agricultural Experiment Station, manuscript 98040 .

Accepted for publication 10 November 1999.

Publication no. D-2000-0125-04R

(C) 2000 The American Phytopathological Society tions in yield $(7,14,26,27)$. The pathogen, Pyricularia grisea Cav., infects rice at all developmental stages, from seedling stages through grain formation, causing leaf blast, collar rot, neck blast, and panicle blast $(14,27)$. Rice blast epidemics often are more severe in temperate and subtropical ecosystems, but they also can occur in other environments if blast-susceptible cultivars are grown or if effective management strategies are not implemented (14).

Rice blast is an economically important disease in Arkansas, particularly on highyielding blast-susceptible cultivars such as Newbonnet (17). Most rice cultivars grown in Arkansas are considered to be susceptible to the contemporary rice blast races $(P$. grisea races IC17 and IB49) in Arkansas, although the effect of disease resistance on disease development during the growing season has not been quantified $(4,6)$. Several factors influence the occurrence and severity of blast in Arkansas. For example, rate and timing of the application of nitrogen fertilizer may affect the severity of rice blast in Arkansas (25). Even though multiple applications of nitrogen are currently recommended in Arkansas (6), some growers use single applications early in the growing season in an effort to reduce production costs. Also, single applications of $\mathrm{N}$ fertilizer are being considered for some of the newer cultivars that do not respond to midseason (panicle differentiation [PD]) application (6).

Kurschner et al. (16) reported that while nitrogen was essential for productivity, the severity of blast also increased with the rate of application. Several studies have shown that excessive nitrogen increases the susceptibility of the rice plant to rice blast $(5,14,16)$. Amin and Venkatorao (2), Templeton et al. (25), and Kurschner et al. (16) either observed or reported that split applications of nitrogen reduced excessive vegetative growth early in the season and reduced the severity of blast. Others have also noted that nitrogen fertilization influenced the size of leaf blast lesions $(11,19)$. Although fungicide applications and cultural practices, such as water management and seeding densities, can be effective tools to help manage leaf and neck blast, information on the effect of nitrogen fertilization on currently grown cultivars is needed to effectively manage rice blast disease in Arkansas $(1,4,9,12,13)$.

The objectives addressed in this study were to quantify disease progress on commercial rice cultivars differing in blast susceptibility, to determine the effects of nitrogen rate and timing on rice blast development early in the season, and to determine if cultivars respond differently to nitrogen treatments in regard to leaf blast development.

\section{MATERIALS AND METHODS}

Eight rice cultivars commonly grown in Arkansas, selected to represent diverse genotypes, maturities, and degrees of susceptibility to $P$. grisea, were grown in replicated field trials at the Pine Tree Branch Experiment Station, Colt, Arkansas, during 
1995 and 1996 (Table 1). Experimental May 1996. The sites were precision leveled for optimum water management and were bordered by trees on the east and north.

The eight cultivars received nitrogen at the recommended rates of 123 to 168 $\mathrm{kg} / \mathrm{ha} /$ year (Table 1), depending on the recommendation for each cultivar $(6,20)$. Three nitrogen (as urea) treatments were tested in a randomized complete block (RCB) design, with four replications of each treatment per cultivar. Plots were drill-seeded at $125 \mathrm{~kg} / \mathrm{ha}$ in $1.5 \times 4.6 \mathrm{~m}$ plots of nine rows spaced $17.5 \mathrm{~cm}$ apart. The first treatment (Normal-N) consisted of nitrogen $(\mathrm{N})$ fertilizer applied at the recommended rate as a single preflood application (initial tillering stage) (28). The second treatment (High-N) consisted of 1.5 times the recommended rate of $\mathrm{N}$ fertilizer, also applied as a single preflood application. The third nitrogen treatment (Split$\mathrm{N}$ ), the standard for the last 10 years in Arkansas, consisted of the recommended amount of $\mathrm{N}$ fertilizer applied in three separate applications with 56 to $100 \mathrm{~kg} / \mathrm{ha}$ (depending on cultivar) of the $\mathrm{N}$ fertilizer applied at preflood and the remaining 67 $\mathrm{kg} / \mathrm{ha}$ of $\mathrm{N}$ fertilizer applied 10 and 20 days after PD stage (28) in two equal applications of $34 \mathrm{~kg} / \mathrm{ha}(6,20)$.

Inoculation of spreader plots. Rice blast often occurs naturally at the experimental site; nevertheless, artificial inoculation of susceptible "spreader" cultivars (a mixture of M201, M203, and L203) was used to increase disease likelihood. Spreader plots were planted at a seeding rate of $125 \mathrm{~kg} / \mathrm{ha}$ in $1.5 \times 4.8 \mathrm{~m}$ plots of nine rows with $17.5 \mathrm{~cm}$ between rows. Spreader plots bordered all sides of each plot so that plots would be equally exposed to secondary inoculum. Spreader plants were inoculated with $P$. grisea races IB49 and IC17 at the midtillering stage of rice development, approximately 4 weeks after planting. Seven cultivars used in these plots were planted 19 April 1995 and 3

studies were susceptible to these two races of $P$. grisea. Conidia of each race were harvested separately from 7- to 10-day-old cultures grown on potato dextrose agar (PDA; Difco Laboratories, Detroit, MI) incubated under continuous light at $25^{\circ} \mathrm{C}$. Conidial suspensions of each race were adjusted to $5 \times 10^{5}$ conidia per $\mathrm{ml}$ and combined in equal volumes prior to inoculation. Xanthan gum ( $0.4 \mathrm{~g} / \mathrm{liter})$ and Silwet $\mathrm{L} 77$ ( $0.2 \mathrm{ml} / \mathrm{liter})$ were added to the spore suspensions just before inoculation. Two inoculations, 4 days apart, were made on 19 and 23 May 1995 and 27 and 31 May 1996 at the midtillering stage within the spreader plots. Inoculations were made between 2200 and 2400 hours using a compressed air sprayer. The following morning, plots were covered with a shade cloth at approximately 0600 hours to prolong leaf wetness within the canopy. The cloth was removed approximately 30 to 32 $\mathrm{h}$ after inoculation.

Flood irrigation was employed 1 day after the inoculation of $P$. grisea and was maintained at a depth of 10 to $15 \mathrm{~cm}$ throughout the season, as recommended for commercial production (4,6). However, since draining rice fields can increase the incidence and severity of rice blast $(4,6,12)$, the plots were drained two times (26 May and 7 June 1995 and 4 and 16 June 1996) for approximately 5 to 7 days prior to the PD growth stage.

Assessments of disease progress. The incidence and severity of leaf blast, collar rot, and neck blast symptoms were assessed at 7-day intervals beginning 1 week after inoculation of the spreader plots. All leaves on 12 arbitrarily selected plants in each plot were examined to determine the number and size of the leaf blast lesions. Disease incidence was calculated as the percentage of plants that had at least one lesion. Disease incidence of flag leaf collar rot and neck blast was determined at the end of each season by examining 50 arbitrarily collected panicles in each plot.

Table 1. Nitrogen fertilization treatments and rice blast reactions for rice cultivars used in 1995 and 1996 field tests conducted at the Pine Tree Experiment Station, Colt, AR

\begin{tabular}{lcccc}
\hline & \multicolumn{3}{c}{ Nitrogen applications $\mathbf{( k g / h a )}^{\mathbf{a}}$} & \\
\cline { 2 - 4 } Cultivar & Split-N & Normal-N & High-N & Resistance $^{\mathbf{b}}$ \\
\hline Kaybonnet & $84-34-34$ & 151 & 227 & 1 \\
Cypress & $100-34-34$ & 168 & 252 & 5 \\
Lacassine & $100-34-34$ & 168 & 252 & 6 \\
Mars & $56-34-34$ & 123 & 185 & 6 \\
Alan & $84-34-34$ & 151 & 227 & 7 \\
Adair & $67-34-34$ & 134 & 202 & 6 \\
Newbonnet & $84-34-34$ & 151 & 227 & 8 \\
RT7015 & $84-34-34$ & 151 & 227 & 8 \\
\hline
\end{tabular}

${ }^{a}$ Split- $\mathrm{N}$ was three applications of $\mathrm{N}$ where most of the $\mathrm{N}$ (urea) was applied before the first permanent flood at the midtillering stage. The remaining $67 \mathrm{~kg} / \mathrm{ha}$ was applied at midseason (i.e., PD growth stage) in two applications of $34 \mathrm{~kg} / \mathrm{ha} 10$ days apart. Normal-N treatments consisted of the recommended $\mathrm{N}$ amounts as a single application before the first permanent flood during midtillering stage of plant development. High- $\mathrm{N}$ treatments consisted of $\mathrm{N}$ applied at 1.5 times the recommended $\mathrm{N}$ rate applied in a single treatment before the first permanent flood during midtillering stage of plant development.

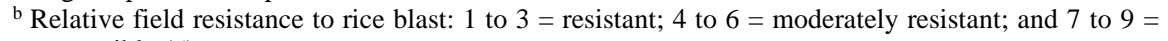
susceptible (6).
The total lesion area per plant also was determined by counting the total number of lesions per plant and measuring each lesion length and width. The summation of these measurements was reported as total lesion area per plant. Lesion area of each lesion was calculated as described by Pinnschmidt et al. (21) according to the equation:

Lesion area $=$

$\frac{\text { width }}{15}\left[(6 *\right.$ length $\left.)+8\left(\sqrt{\left(\text { width }^{2}+\text { length }^{2}\right) / 4}\right)\right]$

where width is the width of a lesion at its widest point and length is the length of a lesion at its longest point.

Statistical analysis. The effect of the three nitrogen treatments on leaf blast development was determined over the assessment period by calculating the area under the disease progress curves (AUDPC). Statistical analyses of AUDPCs were calculated for both disease incidence and total lesion area per plant data. AUDPC values were subjected to analysis of variance (AOV) with the GLM and protected LSD procedures in SAS (1990, SAS Institute, Cary, NC).

Furthermore, the effect of the three nitrogen treatments on leaf blast development was assessed when leaf blast was at a maximum (17 July 1995 and 8 August 1996) and at the end of each season (prior to panicle emergence) (28). These two sampling dates represent potentially important rice growth stages during leaf blast development that may be important in subsequent neck blast infections and yield loss $(3,4,14,26)$. Data taken at these two sampling points were analyzed as described above.

\section{RESULTS}

Symptoms of blast were observed on seven of the cultivars examined for all three N treatments in both 1995 and 1996 (Fig. 1). No disease was observed on the resistant cultivar, Kaybonnet, during the 2 years (data not shown). Disease incidence was considerably higher in 1996 (average disease incidence at PD growth stage on the control treatment was $68 \%$ ) than in 1995 (average disease incidence at PD growth stage on the control treatment was 19\%). These differences in disease incidence were attributed to higher temperatures and less rainfall observed in 1995 compared with 1996. Although foliar disease incidence differed among the cultivars and $\mathrm{N}$ treatments for both years, the disease progress curves generally followed a unimodal pattern (Fig. 1). Disease incidence increased early in the season, consistently reached a maximum near midseason at the PD growth stage, and then generally declined toward the end of the season. This unimodal pattern was observed on the majority of the cultivars 
regardless of $\mathrm{N}$ treatment. Furthermore, not only did the disease incidence (the percentage of plants with at least one lesion) decline after PD growth stage (Fig. 1), but there was also a decline in the total lesion area per plant observed following PD growth stage to panicle emergence (Fig. 2).

Significant differences in disease development were observed among the eight cultivars examined. Based on the lack of rice blast development on Kaybonnet, this cultivar was considered immune. Kaybonnet was omitted from further consideration, since no disease was observed for the specified $\mathrm{N}$ treatments during the course of these studies.

The effect of nitrogen fertilization on the incidence of rice blast. The effect of the $\mathrm{N}$ treatments on leaf blast incidence was similar in 1995 and 1996, even though the incidence and severity were less in 1995 than in 1996. In both years, significant differences between nitrogen treat- ments $(P=0.0001)$, cultivars $(P=0.0001)$, and the nitrogen treatment $\times$ cultivar interactions $(P=0.0001)$ were found when analyzing AUDPC values. Furthermore, significant differences were found between the year $\times$ treatment interaction $(P=$ 0.0203). Due to the differences in disease pressure over the 2 years, combining data did not separate $\mathrm{N}$ treatments that were significantly different both years when data were analyzed separately. These differences were noted as a magnitude effect of
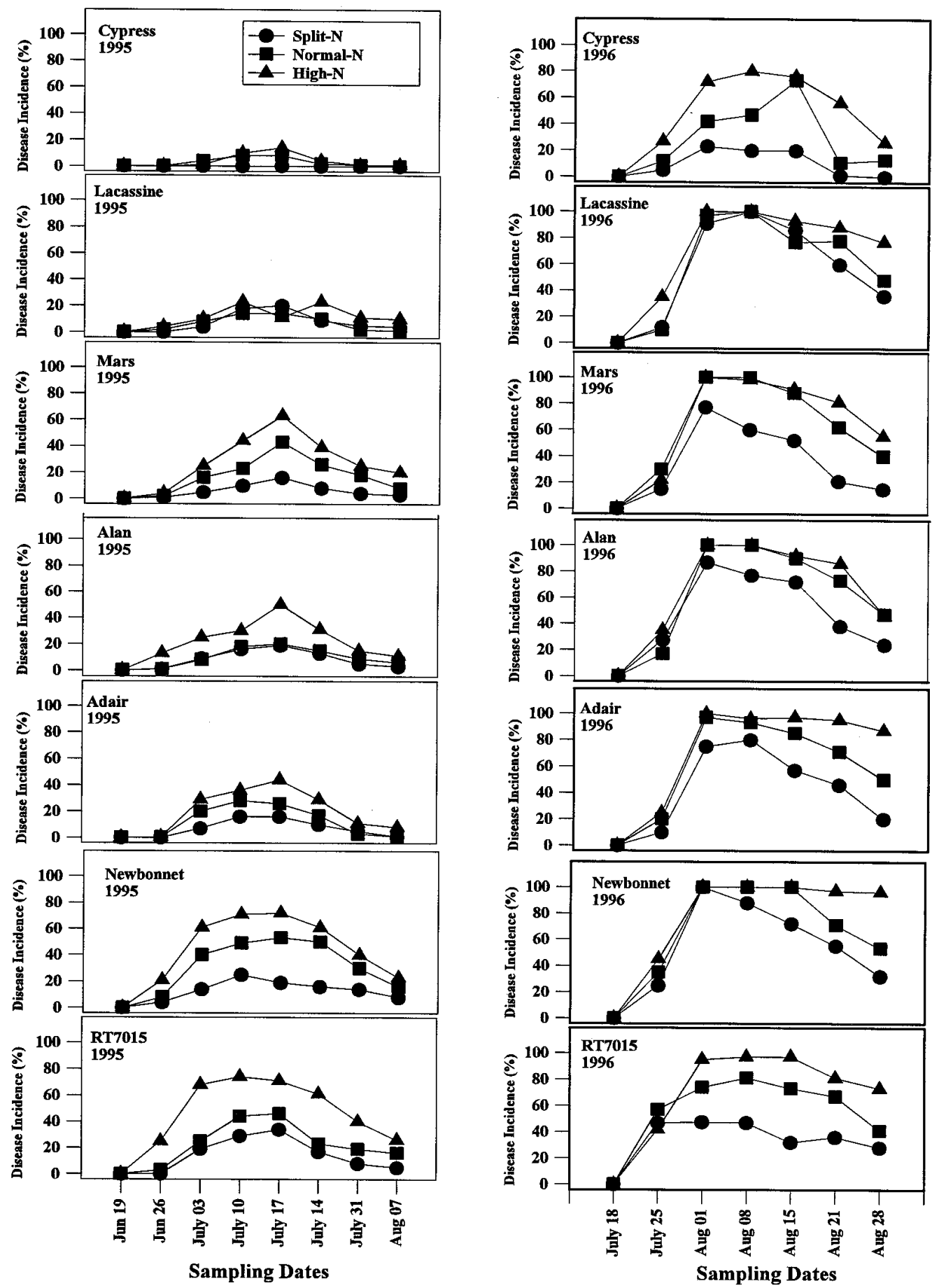

Fig. 1. Disease progress curves for leaf blast incidence (as \%) on rice cultivars Cypress, Lacassine, Mars, Alan, Adair, Newbonnet, and RT7015 fertilized with nitrogen $(\mathrm{N})$ applied at the recommended rate applied as a single application, as a three-way-split application, or as a single application of $\mathrm{N} 1.5$ times the recommended rate in small plots. Experiments were planted 19 April 1995 and 6 May 1996. 
disease levels observed during the 2 years; therefore data from 1995 and 1996 were not combined and are presented separately. During both years, the High-N treatment was generally greater than the Normal-N and the Split-N treatments when measuring disease incidence (average leaf blast incidences at panicle primordia stage were 73 , 60 , and $43 \%$, respectively) or total lesion area per plant (average leaf blast incidences at panicle primordia stage were 118,59 , and $26 \mathrm{~mm}^{2}$, respectively). (Figs. 1 and 2, Table 2).

Statistical analysis. In 1995, analysis of the AUDPC data indicated that there were significant differences among cultivars and $\mathrm{N}$ treatments for disease incidence and total lesion area per plant (Table 2). Furthermore, the effects of $\mathrm{N}$ treatments were cultivar dependent. For example, the High$\mathrm{N}$ treatment significantly increased disease incidence and total lesion area per plant on the susceptible cultivars Newbonnet and RT7015 more than on any other cultivars tested when compared with the Normal-N and the Split-N treatments. Differences between AUDPC values for the High-N and the Split-N treatments were 1,727 and 1,738 for Newbonnet and RT7015, respectively, while these differences were smaller and not statistically significant for Lacassine and Cypress (213 and 211, respectively). The effect of nitrogen on disease incidence and total lesion area per plant on Lacassine and Cypress was relatively small compared with the other cultivars.

In 1996, the High-N and the Normal-N treatments again significantly increased disease incidence and the total lesion area per plant for all cultivars when compared with the Split-N treatment (Fig. 1 and Table 2). The AUDPC values for disease incidence and total lesion area per plant also indicated differences between cultivars at the specified $\mathrm{N}$ treatments (Table 2). For example, the difference between AUDPC values for the High-N and the Split-N treatments for RT7015 was 1,585, while the difference for Cypress was only 27. AUDPC values for disease incidence were significantly higher for the High-N treatment for all cultivars except Mars and Lacassine when compared with the Normal-N treatment. However, AUDPC values for total lesion area per plant indicated significant differences among all nitrogen treatments and all cultivars, including Mars and Lacassine.

In 1995 and 1996, significant differences between nitrogen treatments $(P=0.0001)$, cultivars $(P=0.0001)$, and nitrogen treatment $\times$ cultivar interaction were determined for leaf blast incidence recorded
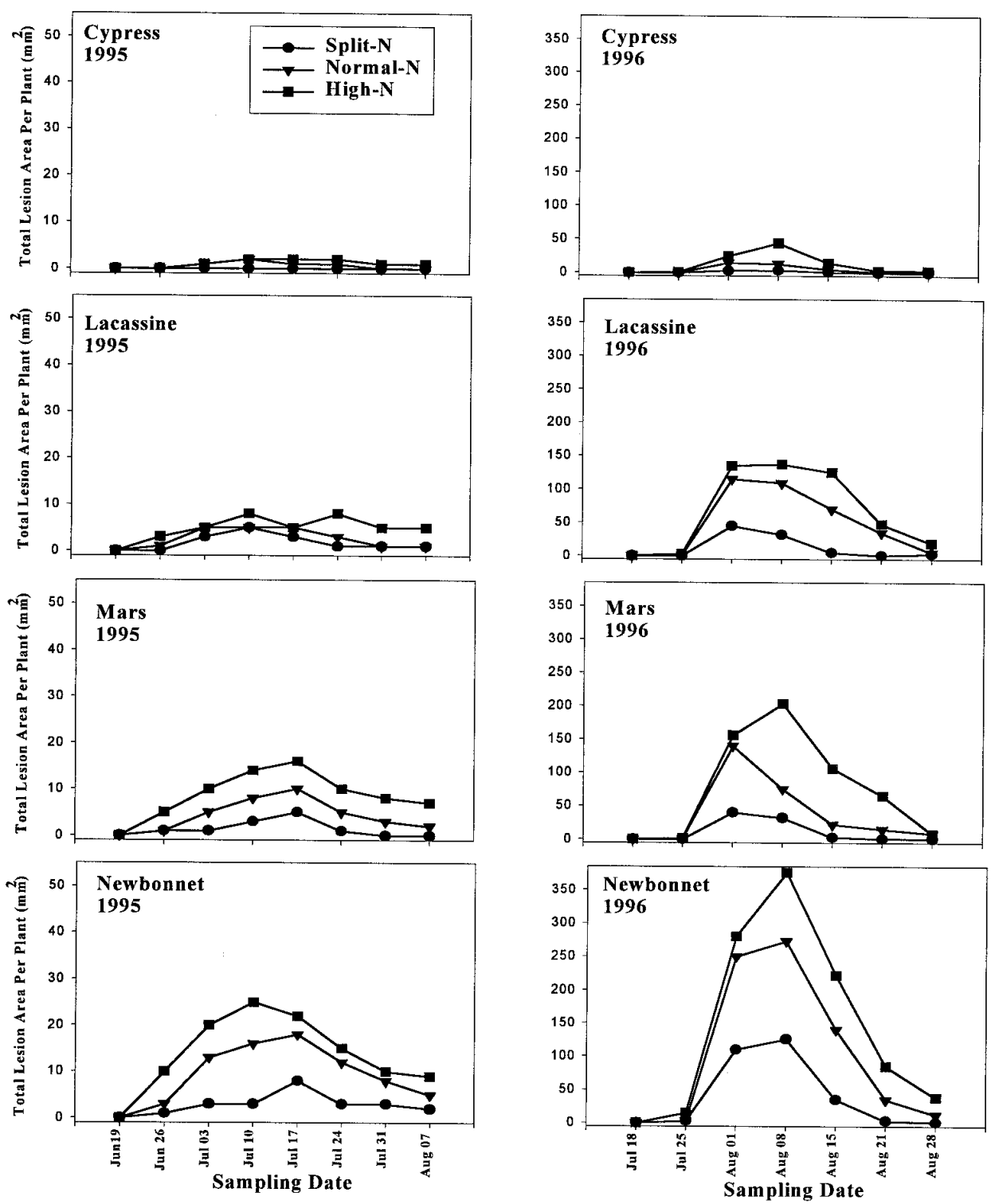

Fig. 2. Disease progress curves for total lesion area (leaf blast) on rice cultivars Cypress, Lacassine, Mars, and Newbonnet fertilized with nitrogen (N) applied at the recommended rate applied as a single application, as a three-way-split application, or as a single application of $\mathrm{N} 1.5$ times the recommended rate in small plots. Experiments were planted 19 April 1995 and 6 May 1996. 
during the midseason peak (PD growth stage) and at the end of the season (late boot stage). In 1995, significant differences between cultivars and $\mathrm{N}$ treatments were observed during maximum leaf blast (PD growth stage) when analyzing both leaf blast incidence and total lesion area per plant (Table 3). The effects of the High-N treatment, when compared with the other $\mathrm{N}$-treatments, were generally greater on the susceptible cultivars RT7015, Newbonnet,
Adair, and Alan. Likewise, the effects of the High-N treatment on leaf blast incidence observed at the end of the season were greater on RT7015, Newbonnet, and Mars, and were significantly different from those receiving the Split-N treatment (Table 4). Differences between the High-N and the Split-N treatment were not the same for all cultivars, in that differential responses to $\mathrm{N}$ treatments between cultivars were observed.
In 1996, the Split-N treatment resulted in lower leaf blast incidence and total lesion area per plant (Fig. 1 and Table 3) than other $\mathrm{N}$-treatments at midseason (PD growth stage). No differences in disease incidence between High-N and Normal-N treatments were observed, except for cultivars RT7015 and Cypress (differences of 17 and $33 \%$, respectively). However, significant differences in total lesion area per plant (a more precise measurement of dis-

Table 2. Area under the disease progress curve (AUDPC) for disease incidence and total lesion area per plant caused by Pyricularia grisea on seven cultivars and three nitrogen treatments planted on 19 April 1995 and 6 May 1996

\begin{tabular}{|c|c|c|c|c|c|c|c|c|c|c|c|c|}
\hline \multirow[b]{3}{*}{ Cultivar } & \multicolumn{6}{|c|}{$\operatorname{AUDPC}(\mathbf{1 9 9 5})^{\mathrm{a}}$} & \multicolumn{6}{|c|}{ AUDPC (1996) } \\
\hline & \multicolumn{3}{|c|}{$\%$ disease incidence ${ }^{b}$} & \multicolumn{3}{|c|}{ Total lesion area ${ }^{c}$} & \multicolumn{3}{|c|}{$\%$ disease incidence } & \multicolumn{3}{|c|}{ Total lesion area } \\
\hline & Split-N ${ }^{d}$ & Normal-N & High-N & Split-N & Normal-N & High-N & Split-N & Normal-N & High-N & Split-N & Normal-N & High-N \\
\hline Cypress & $1^{\mathrm{a}}$ & 163 & 212 & 0.1 & 30 & 61 & 489 & 1,141 & 2,268 & 94 & 242 & 775 \\
\hline Lacassine & 401 & 349 & 614 & 92 & 139 & 264 & 2,683 & 2,980 & 2,710 & 567 & 2,346 & 3,280 \\
\hline Mars & 311 & 928 & 1,485 & 56 & 229 & 417 & 1,628 & 2,804 & 2,950 & 510 & 1,759 & 4,079 \\
\hline Alan & 447 & 582 & 1,203 & 104 & 215 & 507 & 1,949 & 2,746 & 3,194 & 702 & 1,555 & 3,552 \\
\hline Adair & 382 & 657 & 1,083 & 125 & 287 & 520 & 2,216 & 2,828 & 3,059 & 879 & 2,337 & 5,168 \\
\hline Newbonnet & 677 & 1,667 & 2,404 & 154 & 478 & 748 & 2,495 & 3,030 & 3,434 & 1,803 & 4,946 & 7,344 \\
\hline RT7015 & 770 & 1,193 & 2,508 & 289 & 548 & 1,170 & 1,570 & 2,648 & 3,155 & 586 & 1,875 & 3,743 \\
\hline $\operatorname{LSD}(0.05)^{\mathrm{e}}$ & & 257 & & & 84 & & & 190 & & & 265 & \\
\hline
\end{tabular}

a Total area under the disease progress curve ( $\mathrm{x}$-axis $=$ days).

${ }^{\mathrm{b}}$ Percentage of plants with at least one lesion.

c Amount of diseased tissue per plant $\left(\mathrm{mm}^{2}\right)$.

${ }^{\mathrm{d}}$ See Table 1 for nitrogen treatments.

${ }^{\mathrm{e}}$ Least significant difference for AUDPC values for both cultivar and nitrogen treatment.

Table 3. Incidence and severity of leaf blast during the panicle differentiation (PD) growth stage on seven rice cultivars with three nitrogen treatments sampled on 19 July 1995 and 8 August 1996

\begin{tabular}{|c|c|c|c|c|c|c|c|c|c|c|c|c|}
\hline \multirow[b]{3}{*}{ Cultivar } & \multicolumn{6}{|c|}{1995} & \multicolumn{6}{|c|}{1996} \\
\hline & \multicolumn{3}{|c|}{$\%$ disease incidence $^{a}$} & \multicolumn{3}{|c|}{ Total lesion areab } & \multicolumn{3}{|c|}{$\%$ disease incidence } & \multicolumn{3}{|c|}{ Total lesion area } \\
\hline & Split-Nc & Normal-N & High-N & Split-N & Normal-N & High-N & Split-N & Normal-N & High-N & Split-N & Normal-N & High-N \\
\hline Cypress & 0 & 11 & 14 & 0 & 2 & 2 & 20 & 47 & 80 & 4 & 13 & 44 \\
\hline Lacassine & 20 & 15 & 23 & 5 & 5 & 8 & 100 & 100 & 100 & 32 & 109 & 137 \\
\hline Mars & 16 & 43 & 63 & 3 & 10 & 16 & 61 & 99 & 99 & 32 & 75 & 203 \\
\hline Alan & 19 & 20 & 50 & 5 & 7 & 17 & 78 & 100 & 100 & 49 & 121 & 215 \\
\hline Adair & 18 & 28 & 44 & 6 & 12 & 20 & 79 & 94 & 96 & 43 & 51 & 119 \\
\hline Newbonnet & 25 & 55 & 75 & 6 & 16 & 24 & 88 & 100 & 100 & 126 & 273 & 376 \\
\hline RT7015 & 34 & 48 & 75 & 13 & 21 & 37 & 47 & 81 & 98 & 35 & 112 & 210 \\
\hline $\operatorname{LSD}(0.05)^{\mathrm{d}}$ & & 7 & & & 2 & & & 3 & & & 14 & \\
\hline
\end{tabular}

${ }^{a}$ Percentage of plants with at least one lesion.

${ }^{\mathrm{b}}$ Amount of diseased tissue per plant $\left(\mathrm{mm}^{2}\right)$.

${ }^{\mathrm{c}}$ See Table 1 for nitrogen treatments.

${ }^{\mathrm{d}}$ Least significant difference for AUDPC values for both cultivar and nitrogen treatment.

Table 4. Incidence and severity of leaf blast during the late boot stage on seven cultivars with three nitrogen treatments sampled on 7 August 1995 and 28 August 1996

\begin{tabular}{|c|c|c|c|c|c|c|c|c|c|c|c|c|}
\hline \multirow[b]{3}{*}{ Cultivar } & \multicolumn{6}{|c|}{1995} & \multicolumn{6}{|c|}{1996} \\
\hline & \multicolumn{3}{|c|}{$\%$ disease incidence $^{\mathrm{a}}$} & \multicolumn{3}{|c|}{ Total lesion areab } & \multicolumn{3}{|c|}{$\%$ disease incidence } & \multicolumn{3}{|c|}{ Total lesion area } \\
\hline & Split-Nc & Normal-N & High-N & Split-N & Normal-N & High-N & Split-N & Normal-N & High-N & Split-N & Normal-N & High-N \\
\hline Cypress & 0 & 0 & 1 & 0 & 0 & 1 & 0 & 13 & 26 & 0 & 1 & 3 \\
\hline Lacassine & 4 & 1 & 10 & 1 & 1 & 5 & 36 & 48 & 77 & 3 & 5 & 19 \\
\hline Mars & 3 & 8 & 20 & 0 & 2 & 7 & 15 & 38 & 55 & 2 & 9 & 8 \\
\hline Alan & 3 & 6 & 11 & 1 & 3 & 6 & 23 & 46 & 47 & 1 & 8 & 17 \\
\hline Adair & 1 & 1 & 8 & 1 & 1 & 6 & 20 & 50 & 87 & 1 & 6 & 33 \\
\hline Newbonnet & 8 & 16 & 23 & 2 & 5 & 9 & 32 & 53 & 96 & 1 & 12 & 38 \\
\hline RT7015 & 5 & 16 & 26 & 2 & 8 & 13 & 28 & 41 & 73 & 2 & 8 & 26 \\
\hline $\operatorname{LSD}(0.05)^{\mathrm{d}}$ & & 5 & & & 2 & & & 7 & & & 3 & \\
\hline
\end{tabular}

a Percentage of plants with at least one lesion.

b Amount of diseased tissue per plant $\left(\mathrm{mm}^{2}\right)$.

c See Table 1 for nitrogen treatments.

${ }^{\mathrm{d}}$ Least significant difference for AUDPC values for both cultivar and nitrogen treatment. 
ease) were observed among all nitrogen treatments for all cultivars (Table 3). Furthermore, disease incidence and total lesion area per plant data collected at the end of the season indicated significantly less leaf blast in the Split-N treatment when compared with the Normal-N and High-N treatments (Table 4) for all cultivars. Increases in disease incidence for the High-N treatment compared with the Normal-N treatment were observed for all cultivars except Adair (Figs. 1 and 2, and Table 4). Also, significant differences between the High-N and the Normal-N treatments were observed for all cultivars except Mars and Cypress when measuring total lesion area (Fig. 2 and Table 4).

Development of collar rot and neck blast. The incidences of flag leaf collar rot infections observed in 1996 (average collar rot incidence on the control treatment was $38 \%$ ) were higher than those observed in 1995 (average collar rot incidence on the control treatment was only 4\%) (Table 5). During both years, there was a tendency for the more susceptible cultivars such as Newbonnet, Lacassine, and Adair to have higher collar rot incidences than the more resistant cultivars. The effect of nitrogen on the incidence of collar rot was only significant (High-N versus Split-N) for one of the most susceptible cultivars, Newbonnet, in 1995 and 1996 (Table 5). The effect of nitrogen on collar rot incidence in 1995 and 1996 was less than that observed for leaf blast.

The incidence of neck blast was greater in 1996 (average neck blast incidence on the control treatment was 54\%) than in 1995 (average neck blast incidence on the control treatment was 13\%) on all cultivars (Tables 5). The incidence of neck blast was generally greater in the Normal-N and High-N treatments when compared with the Split-N treatment (Table 5); although the effect of nitrogen on neck blast incidence was less than that observed for leaf blast. Significant differences between the High-N and Split-N treatments for neck blast incidence were observed on cultivars RT7015 and Newbonnet in 1995 (differ- ences of 31 and $41 \%$, respectively), and only on Newbonnet (difference of $30 \%$ ) in 1996 (Table 5).

\section{DISCUSSION}

The interaction of cultivars $\times$ nitrogen on rice blast was quantified in 1995 and 1996 on commercial cultivars commonly grown in Arkansas. These studies illustrate four important points regarding the development of rice blast in Arkansas.

First, a simple unimodal disease progress curve described leaf blast development on most of the susceptible cultivars, in that leaf blast, whether measured as disease incidence or as total lesion area per plant, increased from low levels early in the season (vegetative growth stages) to the highest levels at midseason (PD growth stage), and then declined gradually thereafter (reproductive growth stages). To our knowledge, this is the first report that quantitatively describes the development of rice blast during the growing season in Arkansas and the southern U.S. rice-producing regions. In field studies conducted at the International Rice Research Institute in the Philippines, Bastiaans (3) described a decline in leaf blast and attributed it to the death of diseased leaves and to the formation of new leaf tissue (nondiseased). $\mathrm{He}$ also reported that the aging rice leaves become increasingly resistant with age to rice blast and that this property was enhanced as the rice plant became physiologically older $(3,7,15)$. Roumen (22) reported that leaf infections on maturing rice plants (reproductive growth stages) exhibited reduced infection efficiency, lesion size, and sporulation when compared with those observed on younger rice plants (vegetative growth stages). These reports support our findings that describe the disease progress of rice blast in Arkansas, in that the peak incidence of leaf blast occurs at the end of the vegetative growth stages and that the rice plant becomes increasingly resistant to rice blast (resulting in less disease) as the rice plant approaches physiological maturity.
Secondly, nitrogen applied as a single application equal to or above the currently recommended amounts (Normal-N or High-N, respectively) significantly and differentially (by cultivar) increased disease incidence and the total lesion area per plant over the Split-N treatment for each susceptible cultivar. This is the first report that suggests a differential cultivar response to $\mathrm{N}$ fertilizer in regard to rice blast. The incidence and severity of leaf blast were significantly lower when $\mathrm{N}$ was applied as a three-split application (Split$\mathrm{N}$ ) on all cultivars when compared with the Normal-N or the High-N treatments. The data were consistent with other studies that have reported the effects of nitrogen on rice blast development and the reduction of leaf blast when using split applications $(2,8,14,16,25)$. Furthermore, these data support previous recommendations in $\mathrm{Ar}$ kansas (three-split-N applications) and signal caution when applying single applications of $\mathrm{N}$ on susceptible cultivars. Kurschner et al. (16) and Templeton et al. (25) observed that split applications of nitrogen avoided excessive vegetative growth early in the season and reduced the severity of rice blast. Our data conclusively show that high amounts of nitrogen applied early in the season during the vegetative growth stage of rice plant development increased disease incidence and total lesion area of rice blast. Sridhar (24) reported that increases in susceptibility to leaf blast occurred in both highly and moderately susceptible cultivars; however, our data suggest that cultivars respond differently to $\mathrm{N}$ fertilization and that the most susceptible cultivars are at a higher risk for leaf blast epidemics than are the more resistant cultivars.

Interestingly, although collar rot and neck blast incidence were generally higher on rice plants receiving the High-N treatment, the differences were not significant. There apparently were no treatment effects for collar rot or neck blast. One plausible explanation for the lack of significance between $\mathrm{N}$ treatments and neck and collar

Table 5. Percent flag leaf collar rot and neck blast on seven cultivars with three nitrogen treatments in tests planted on 19 April 1995 and 6 May 1996

\begin{tabular}{|c|c|c|c|c|c|c|c|c|c|c|c|c|}
\hline \multirow[b]{4}{*}{ Cultivar } & \multicolumn{12}{|c|}{ Incidence $(\%)$} \\
\hline & \multicolumn{6}{|c|}{1995} & \multicolumn{6}{|c|}{1996} \\
\hline & \multicolumn{3}{|c|}{ Collar rot ${ }^{\mathrm{a}}$} & \multicolumn{3}{|c|}{ Neck blast ${ }^{b}$} & \multicolumn{3}{|c|}{ Collar rot } & \multicolumn{3}{|c|}{ Neck blast } \\
\hline & Split-Nc & Normal-N & High-N & Split-N & Normal-N & High-N & Split-N & Normal-N & High-N & Split-N & Normal-N & High-N \\
\hline Cypress & 3 & 0 & 1 & 8 & 0 & 9 & 15 & 13 & 25 & 18 & 21 & 39 \\
\hline Lacassine & 8 & 19 & 22 & 26 & 23 & 42 & 56 & 58 & 74 & 50 & 62 & 68 \\
\hline Mars & 0.3 & 0 & 0.3 & 5 & 0 & 4 & 31 & 30 & 54 & 36 & 45 & 43 \\
\hline Adair & 5 & 4 & 4 & 5 & 11 & 13 & 64 & 64 & 86 & 73 & 78 & 90 \\
\hline Alan & 5 & 11 & 10 & 25 & 37 & 43 & 18 & 31 & 24 & 70 & 64 & 68 \\
\hline Newbonnet & 3 & 5 & 23 & 12 & 30 & 58 & 49 & 69 & 81 & 60 & 78 & 90 \\
\hline RT7015 & 4 & 8 & 8 & 12 & 17 & 43 & 34 & 34 & 34 & 70 & 55 & 75 \\
\hline $\operatorname{LSD}(0.05)^{\mathrm{d}}$ & & 11 & & & 23 & & & 28 & & & 27 & \\
\hline
\end{tabular}

\footnotetext{
${ }^{a}$ Percentage of flag leaves with collar rot symptoms observed from a sample size of 50 plants per replication.

${ }^{b}$ Percentage of neck blast symptoms observed from a sample size of 50 plants per replication.

${ }^{c}$ See Table 1 for nitrogen treatments.

${ }^{\mathrm{d}}$ Least significant difference for AUDPC values for both cultivar and nitrogen treatment.
} 
rot incidence is that the nitrogen was consumed long before neck node emergence (20,25). In addition, the Normal-N and High-N treatments appeared to affect plant maturity more than the Split-N treatment, in that plants generally matured 7 to 10 days later (data not shown). It is likely that the window of infectivity for neck infection is relatively short $(14,27)$. Consequently, differences in conditions during this window could greatly affect the frequency of infection. Roumen (23) reported that age-related resistance and environmental effects also govern the infectivity of necks and subsequent sporulation. Unlike field studies recently conducted in commercial fields in Arkansas (18), leaf blast incidence was not significantly correlated with neck blast incidence in the small plots. In larger fields, Long (18) concluded that the incidence of neck blast was highly correlated with the incidence of leaf blast, especially when there was a high incidence of leaf blast. In the present study, the relationship between the leaf blast incidence and neck blast may have been affected by interplot interference. The experimental design allowed only $0.3-\mathrm{m}$ separation between the $7-\mathrm{m}^{2}$ plots, which may have been insufficient in limiting neck blast from neighboring treatments. Kato et al. (10) reported that neck and panicle infections were major contributors of $P$. grisea conidia in the dissemination and infection of neighboring panicles, and these infections also have a greater sporulation potential and infectious period than leaf blast infections $(10,23)$.

Thirdly, the highest incidence of leaf blast, regardless of the nitrogen treatments, occurred at midseason, when the plants were at the PD stage of growth. This observation may be useful in the detection and management of rice blast. For example, currently in Arkansas, scouting protocols recommend that fields be examined for rice blast just prior to the heading stage (early boot stage) $(4,6)$. However, it may be more useful to examine fields earlier, during the period when leaf blast would be expected to be at its highest, to obtain a more accurate measure of disease at its highest level and to obtain information on the distribution of disease in the field before subsequent fungicide applications are made during panicle emergence $(4,6)$. Since yield losses are more highly correlated with neck blast than with leaf blast $(4,14,26)$, additional work is needed to determine whether the conditions that contribute to higher incidences of leaf blast also contribute to higher incidences of neck rot. Torres and Teng (26) reported that the incidence of neck blast is directly related to yield loss and that leaf and collar infections affect yields less. Bastiaan (3) reported that disease loss assessments caused by leaf blast epidemics have more of an effect on yield when they occur from midtillering to preflowering stages (reproductive stages).

Lastly, rice blast management strategies in Arkansas incorporate the use of disease resistance, cultural practices (i.e., planting densities, water management, and nitrogen fertilization), and fungicides. These strategies contribute to reducing disease development, but their implementation requires accurate information on the probability of disease development based on historical records, effective scouting, and models. The lack of effective management strategies, particularly $\mathrm{N}$ fertilization, water management, and the use of susceptible cultivars, has profound effects on rice blast development. Cultivar selection and implementation of proper management strategies are influenced by the fact that rice blast epidemics in Arkansas are sporadic and may not cause significant problems annually. As shown in this study, increased levels of nitrogen and the timing of application are critical in the management of rice blast. Also, the effects of these nitrogen inputs appear to be cultivar dependent. Since these results indicate a differential cultivar response to nitrogen, selecting cultivars that are resistant or moderately resistant to rice blast may be more desirable (less risky) than selecting cultivars that become increasingly susceptible with increased $\mathrm{N}$ levels.

\section{LITERATURE CITED}

1. Amin, K. S., and Katyal, J. C. 1979. Incidence of leaf blast in relation to seedling density and chemical composition of rice varieties. Phytopathol. Z. 96:65-70.

2. Amin, K. S., and Venkatorao, G. 1979. Rice blast control by nitrogen management. Phytopathol. Z. 96:140-145.

3. Bastiaans, L. 1993. Understanding yield reduction in rice due to leaf blast. Ph.D. thesis. Wageningen Agricultural University, Wageningen, Netherlands.

4. Cloud, G. L., and Lee, F. N. 1993. Rice blast: Factors influencing severity and control strategies used to manage the disease. Arkansas Cooperative Extension Service, Misc. Publ. 341.

5. Correa, F., and Zeigler, R. 1991. Manejo integrando del anublo del arroz (Pyricularia oryzae). Fitopatol. Colomb. 15:35-39.

6. Helms, R. S., ed. 1990. Rice Production Handbook. University of Arkansas Cooperative Extension Service. Misc. Publ. 192.

7. Hwang, B. K., Koh, Y. J., and Chung, H. S. 1987. Effects of adult-plant resistance on blast severity and yield of rice. Plant Dis. 71:1035-1038.

8. Ishiguro, K. 1994. Using simulation models to explore better strategies for the management of blast disease in temperate rice pathosystems. Ch. 25, pp. 435-450. Rice Blast Disease. R. S. Zeigler, ed. IRRI, Los Banos, Philippines.

9. Jayachandran-Nair, K., and Charkrabarti, N. K. 1980. Incidence of Pyricularia oryzae and biochemical changes in the rice plants grown under upland conditions. Phytopathol. Z. 98:359-367.
10. Kato, H., Tsugio, S., and Koshimizu, Y. 1970. Potential for conidium formation of Pyricularia oryzae in lesions on leaves and panicles on rice. Phytopathology 60:608612.

11. Kaur, S., Padmanabhan, P., and Kaur, P. 1979. Effect of nitrogen on the intracellular spread of Pyricularia oryzae. Phytopathology 69:285-286.

12. Kim, C. H., and Kim, C. K. 1990. Rice blast development under different water-management practices in fields in Korea. Korean J. Plant Pathol. 6:51-57.

13. Kim, C. H., Rush, M. C., and Mackenzie, D. R. 1986. Effect of soil moisture on histopathology of blast development in rice. Pages 86-87 in: Proc. Rice Tech. Working Grp., 21 st.

14. Kingsolver, C. H., Barksdale, T. H., and Marchetti, M. A. 1984. Rice blast epidemiology. Agricultural Experiment Station Bull. 853. Pennsylvania State University, College of Agriculture, University Park.

15. Koh, Y. J., Hwang, B. K., and Chung, H. S. 1987. Adult-plant resistance of rice to leaf blast. Phytopathology 77:232-236.

16. Kurschner, E., Bonman, J. M., Garrity, D. P., Tamisin, M. M., Pabale, D., and Estrada, B. A. 1992. Effects of nitrogen timing and split application on blast disease in upland rice. Plant Dis. 76:384-389.

17. Lee, F. N. 1994. Rice breeding programs, blast epidemics and blast management in the United States. Ch. 28, pp. 489-500. Rice Blast Disease. R. S. Zeigler, ed. IRRI, Los Banos, Philippines.

18. Long, D. H. 1996. The epidemiology of rice blast disease in Arkansas. M.S. thesis. University of Arkansas, Fayetteville.

19. Matsuyama, N., and Dimond, A. E. 1973 Effect of nitrogenous fertilizer on biochemical processes that could affect lesion size of rice blast. Phytopathology 63:1202-1203.

20. Norman, R. J., Wilson, C. E., Jr., Wells, B. R., Ntamatungario, S., Slaton, N. A., Gravois, K. A., and Moldenhauer, K. A. K. 1995. Management of agronomic factors in rice production. Pages 169-177 in: Arkansas Rice Research Studies 1994. B. R. Wells, ed. Arkansas Agricultural Experiment Station, Res. Ser. 446. University of Arkansas, Fayetteville.

21. Pinnschmidt, H. O., Teng, P. S., Bonman, J. M., and Kranz, J. 1993. A new assessment key for leaf blast (Bl). IRRN 18:145-146.

22. Roumen, E. C. 1992. Effect of leaf age on components of partial resistance in rice to leaf blast. Euphytica 63:271-279.

23. Roumen, E. C. 1993. Partial resistance to neck blast influenced by stage of panicle development and rice genotype. Euphytica 64:173-182.

24. Sridhar, R. 1972. Influence of nitrogen fertilization and Piricularia oryzae development on some oxidase, their substrates and respiration of rice plants. Acta Phytopathol. Acad. Sci. Hung. 7:57-70.

25. Templeton, G. E., Wells, B. R., and Johnston, T. H. 1970. N-fertilizer application closely related to blast at nodes and resultant lodging of rice. Rice J. 73:1.

26. Torres, C. Q., and Teng, P. S. 1993. Path coefficient and regression analysis of the effects of leaf and panicle blast on tropical rice yield. Crop Prot. 12:296-302.

27. Webster, R. K., and Gunnell, P. S. 1992. Compendium of Rice Diseases. American Phytopathological Society, St. Paul, MN.

28. Yoshida, S. 1981. Fundamentals of rice crop science. IRRI, Los Banos, Philippines. 